\title{
Cadmium Tolerance During Seed Germination and Seedling Growth of Schinus molle (Anacardiaceae)
}

\author{
Gabriel de Resende Baroni ${ }^{1}$ (1) 0000-0001-6261-4671 \\ Márcio Paulo Pereira² (10) 0000-0002-9245-7029 \\ Felipe Fogaroli Corrêa ${ }^{2}$ (1) 0000-0002-9072-0436 \\ Evaristo Mauro de Castro ${ }^{2}$ (1) 0000-0002-1385-8503 \\ Fabrício José Pereira ${ }^{3}$ (10 0000-0002-8132-0625
}

\begin{abstract}
Cadmium (Cd) is one of the most toxic elements to plants, so Cd-tolerant trees should be used in reforestation or remediation systems. In this study the effects of $\mathrm{Cd}$ on seed germination and early seedling growth were evaluated in Schinus molle plants. Seeds of S. molle were treated with Cd at concentrations of 0 (control), 0.01, 0.02, 0.05, and $0.125 \mathrm{mM}$ using $\mathrm{Cd}\left(\mathrm{NO}_{3}\right)_{2}$. Seed germination parameters and seedling growth traits were evaluated 33 days after the experiment started. Seeds and roots were sampled for anatomical evaluation and processed with plant microtechniques. No effects of Cd were found on the germination percentage of $S$. molle seeds. However, seedlings' shoot and root fresh masses and lengths increased with Cd treatment. Cadmium increased root cortex and endodermis thickness and reduced the percentage of vascular tissues in seedlings. Schinus molle seeds and seedlings thus showed tolerance to Cd related to anatomical adaptations.
\end{abstract}

Keywords: pepper tree, endodermis, heavy metals, phytoremediation, seed anatomy.

\section{INTRODUCTION AND OBJECTIVES}

Heavy metal pollutants are of increasing concern worldwide, since human activities continue to promote their disposal in the environment. Cadmium (Cd) is one of them, which has high toxicity to plant growth and development (Benavides et al., 2005). Cadmium's toxicity to plants is remarkably intense, so the identification of Cd-tolerant species is particularly difficult (Mangkoedhardjo, 2008). The number of taxa known to be able to hyperaccumulate $\mathrm{Cd}$ is very low compared to those tolerant to other pollutants (Krämer, 2010). The use of woody species in the remediation of polluted environments is called dendroremediation (Gonzälez-Oreja et al., 2008), and is being increasingly applied worldwide. Therefore, finding new Cd-tolerant species is important to develop remediation systems for polluted soils, as well as for its reforestation.

$\mathrm{Cd}$ toxicity is high during seed germination and may decrease seed vigor (Ahmad et al., 2012; Ali et al., 2015; Anuradha \& Rao, 2007; Bautista et al., 2013; He et al., 2008; Tao et al., 2015; Zhang et al., 2012). However, some species can overcome Cd's negative effects, depending on variations in their genotypes or pollutant concentrations (He et al., 2008; Rossi et al., 2012; Tao et al., 2015). Likewise, the growth of roots and shoots of seedlings are both reduced by $\mathrm{Cd}$ in sensitive plant species (Anuradha \& Rao, 2007; Bautista et al., 2013; Tao et al., 2015; Zhang et al., 2012). Seed germination and seedling growth are key processes for plant establishment in polluted environments, so it is essential that Cd tolerance mechanisms within these stages are understood.

The pepper tree, Schinus molle L. (Anacardiaceae), native to South America, is distributed worldwide and used as a medicinal plant or in urban forestation. In a previous study, this species showed tolerance to $\mathrm{Pb}$ during its germination and early growth stages (Pereira et al., 2013). Moreover, S. molle is tolerant to $\mathrm{Cd}$, and low concentrations of this element can cause anatomical modifications in its leaves, as well as photosynthetic responses (Pereira et al., 2016). Likewise, this plant can thrive in different stressful environmental conditions, such as poor soils and droughts (Iponga et al., 2008). Therefore, S. molle shows potential for use in remediation and reforestation systems.

\footnotetext{
${ }^{1}$ Universidade de São Paulo (USP), Piracicaba, SP, Brasil

${ }^{2}$ Universidade Federal de Lavras (UFLA), Lavras, MG, Brasil

${ }^{3}$ Universidade Federal de Alfenas (UNIFAL), Alfenas, MG, Brasil
} 
Although finding new Cd-tolerant species is essential, understanding how plants cope with heavy metal stress is necessary to improve their remediation potential. Data show that plant tolerance to heavy metal toxicity is related to both their physiological and anatomical traits (Pereira et al., 2014; Ribeiro et al., 2015; Silva et al., 2013). Furthermore, Cd-tolerant species can show anatomical modifications that improve their root and leaf anatomy (Pereira et al., 2013). Seed coats also have a role in the uptake of water and other elements by germinating seeds (Malan \& Farrant, 1998; Moïse et al., 2005). Thus, the anatomical structure of seeds and seedlings must be investigated to understand the effects of heavy metals on its seed germination and seedling growth.

Therefore, this study evaluates the effects of $\mathrm{Cd}$ on the germination of Schinus molle seeds and the growth of this species' seedlings, as well as the anatomy of its seedlings' roots.

\section{MATERIALS AND METHODS}

\subsection{Plant material and experimental design}

S. molle seeds were collected from cultivated populations in the southern region of the state of Minas Gerais, Brazil. Seeds were surface sterilized with $50 \%\left(\mathrm{v} \mathrm{v}^{-1}\right)$ sodium hypochlorite and washed twice in distilled water. The seeds were further dried at room temperature and then stored in paper bags at $4{ }^{\circ} \mathrm{C}$ until further analyses were performed according to Pereira et al. (2016).

Seeds were acid-scarified (Pereira et al., 2016) and sown into gearbox-type boxes each containing vermiculite and one of the following Cd solutions: 0 (control), $0.01,0.02,0.05$, and $0.125 \mathrm{mM}$, using $\mathrm{Cd}\left(\mathrm{NO}_{3}\right)_{2}$ as source. Samples were kept in a germination chamber at $25^{\circ} \mathrm{C}$ and under a $24 \mathrm{~h}$ photoperiod for 33 days (Pereira et al., 2016), then seed germination, seedling growth and root anatomy were evaluated.

The experiment used a completely randomized design, with five treatments and six replicates comprised of 25 seeds each.

\subsection{Seed germination and seedling growth analysis}

Germination was quantified as the percentage of seeds that showed radicle protrusion 30 days after the experiment started. Percent germination was calculated by dividing the number of germinated seeds by 25 in each replicate and then multiplying it by 100 . The germination speed index was calculated by the sum number of seeds germinated daily divided by the days passed since the start of the experiment. These seed germination parameters were based on those of Pereira et al. (2016).

The early growth of the seedlings was evaluated at the end of the experiment. Seedling fresh mass was measured with an analytical precision scale (AY 220, Shimadzu, Japan). Seedlings were immediately photographed, and digital images were used to measure shoot and root lengths using the UTHSCSA-Imagetool software.

\subsection{Seedling root anatomy}

Root anatomy was evaluated in seedlings sampled at the end of the experiment. The roots were fixed in a solution of formaldehyde, acetic acid, and 70\% ethanol (F.A.A. 70) for 72 hours, and then stored in $70 \%$ ethanol until further analyses were done (Johansen, 1940). Root sections were made $2 \mathrm{~cm}$ away from the root apex using an LPC model microtome. Sections were cleared with sodium hypochlorite, rinsed in distilled water twice for $10 \mathrm{~min}$, stained with safrablau solution [ $1 \%$ safranin $\left(\mathrm{w} \mathrm{v}^{-1}\right)$ and $0.1 \%$ astra blue $\left(\mathrm{w} \mathrm{v}^{-1}\right)$ at a ratio of $7: 3]$, and put on slides with coverslips in $50 \%$ glycerol. These slides were photographed under a microscope light attached to an image capture system (CX31, Olympus, Tokyo, Japan).

The UTHSCSA-Imagetool software was used for image analysis, in which the following parameters were measured: $\mathrm{EP}=$ epidermis thickness, $\mathrm{ED}=$ endodermis thickness, $\mathrm{CT}=$ cortex thickness, $\mathrm{EX}=$ exodermis thickness, $\mathrm{PR}=$ pericycle thickness, $\mathrm{VC}=$ area of vascular cylinder, $\mathrm{RA}=$ area of whole root in cross-section, $\mathrm{XA}=$ area of xylem in the vascular cylinder, $\mathrm{PA}=$ area of phloem in the vascular cylinder, and $\mathrm{DV}=$ average diameter of xylem tracheary elements in the metaxylem. The percentage of the root cross-sectional area taken up by the vascular cylinder (VC\%) was calculated as $\mathrm{VC} / \mathrm{RA}^{\star} 100$; the percentage of xylem in the vascular cylinder (X\%) was calculated as XA/VC ${ }^{\star} 100$; and the percentage of phloem in the vascular cylinder ( $\mathrm{PH} \%)$ was calculated as $\mathrm{PA} / \mathrm{VC}^{\star} 100$.

Each replicate produced one slide, for which five sections and three fields were evaluated to assess each anatomical characteristic.

\subsection{Statistical analyses}

Data were submitted to statistical analyses in Sisvar 5.0 software (Ferreira, 2011) and to normal distribution test (Shapiro-Wilk), then compared among Cd treatments with a one-way Anova. Means were compared among specific treatments using the Scott-Knott test $(p \leq 0.05)$ or a regression analysis.

\section{RESULTS}

Figure 1 shows that $\mathrm{Cd}$ had no effect on the germination of S. molle seeds. The germination percentage was not significantly affected by $\mathrm{Cd}$ concentration $(\mathrm{Fc}=2.14, \mathrm{p}=0.11)$, nor was the germination speed index $(\mathrm{Fc}=0.83, p=0.52)$. 
The early growth of $S$. molle seedlings was positively affected by Cd (Figure 2). Seedlings' fresh masses and root lengths increased as Cd levels increased (Figure 2a and 2b, respectively). Likewise, shoot length also increased compared to the control with $\mathrm{Cd}$ treatment, but only at lower $\mathrm{Cd}$ concentrations (Figure 2c). (a)

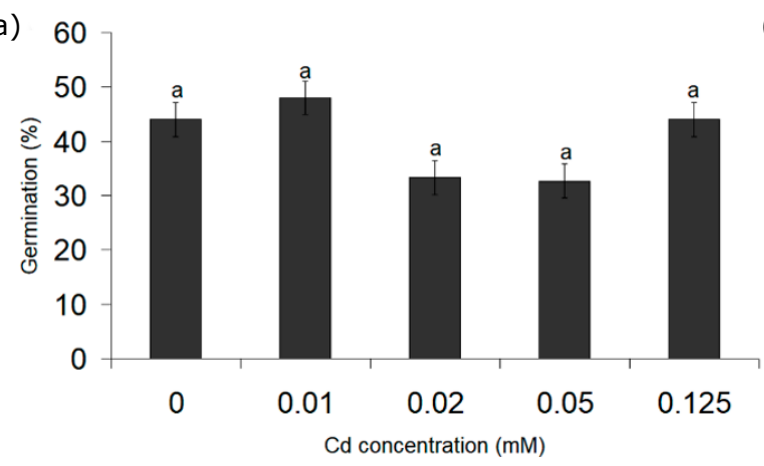

(b)

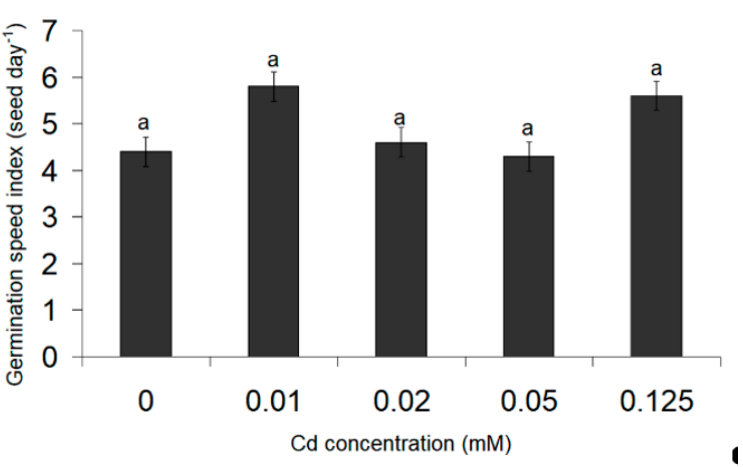

Figure 1. Germination of $S$. molle seeds under conditions with different Cd concentrations. Means followed by the same letter does not differ significantly according to the Scott-Knott test $(p>0.05)$. Error bars indicate standard error values. Coefficients of variation were $15.56 \%$ (a) and $16.74 \%$ (b).

(a)

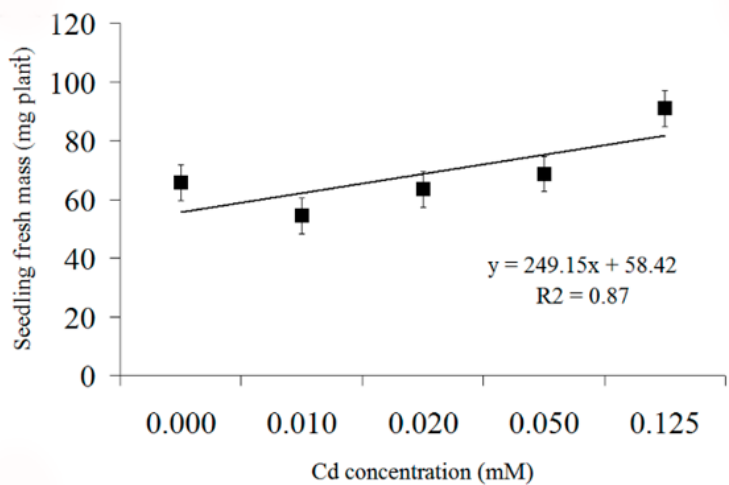

(c)

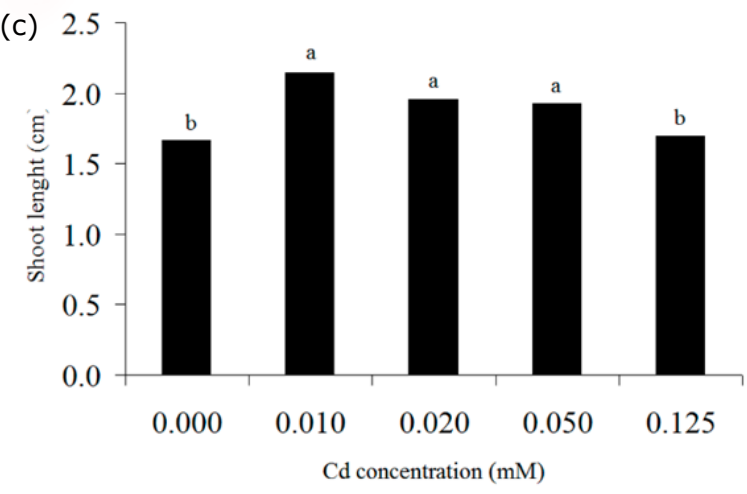

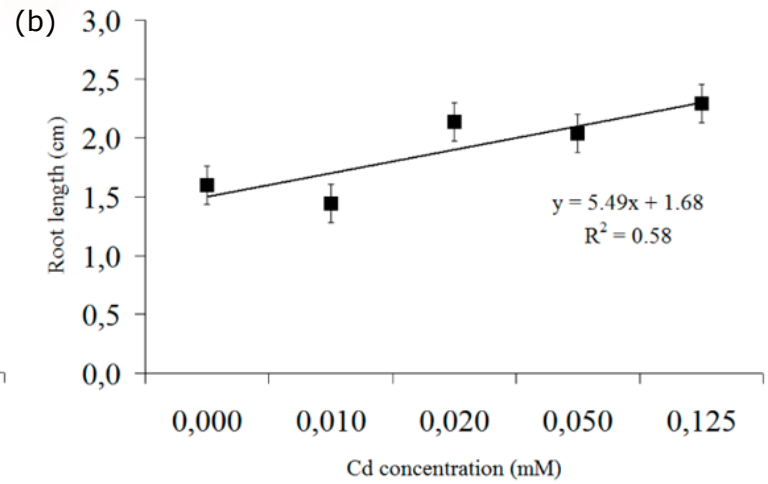

Figure 2. Growth of S. molle seedlings under different Cd concentrations, assessed in terms of fresh mass (a), root length (b), and shoot length (c). In (a) and (b), error bars indicate standard error values. In (c), means followed by the same letter did not differ significantly according to the Scott-Knott test $(p>0.05)$. Coefficients of variation were $16.67 \%(a), 10.71 \%(b)$, and $7.98 \%(c)$. 
Root epidermis $(\mathrm{Fc}=3.92, p>0.05)$ and exodermis $(\mathrm{Fc}=5.65, p>0.05)$ were not modified by $\mathrm{Cd}$ treatment. However, endodermis thickness (Figure 3a), pericycle (Figure $3 b$ ), and cortex (Figure $3 c$ ) were increased by $\mathrm{Cd}$ treatment at lower levels but dropped back again at the highest concentration tested. The average xylem vessel diameter was also increased by treatment with lower Cd levels, but reduced at the highest concentration (Figure 3d). The percentage of the root taken up by the vascular cylinder was reduced by $\mathrm{Cd}$ treatment (Figure 3e), despite no significant differences being found among $\mathrm{Cd}$ treatments for the percentages of xylem and phloem in the vascular cylinder (Figure 3f). (a)

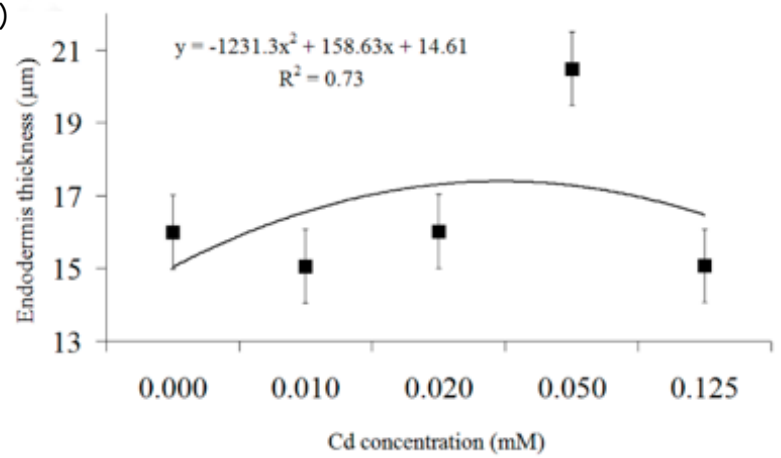

(c)

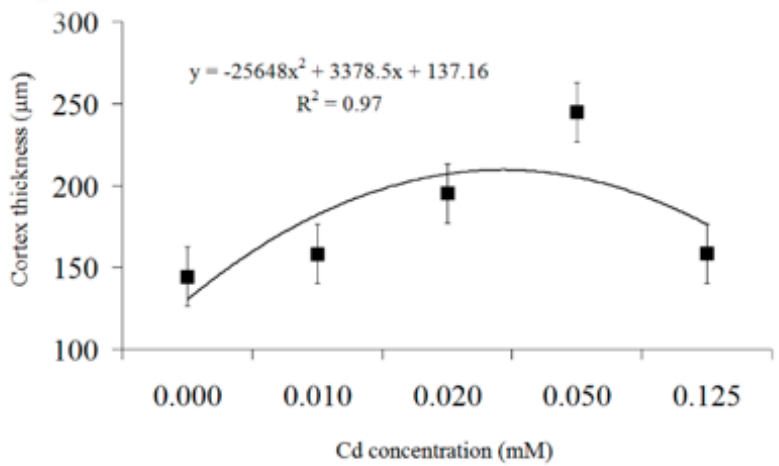

(e)

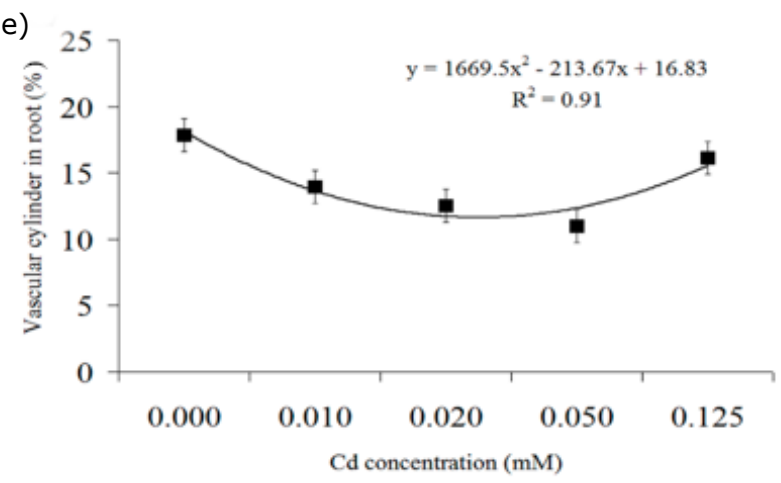

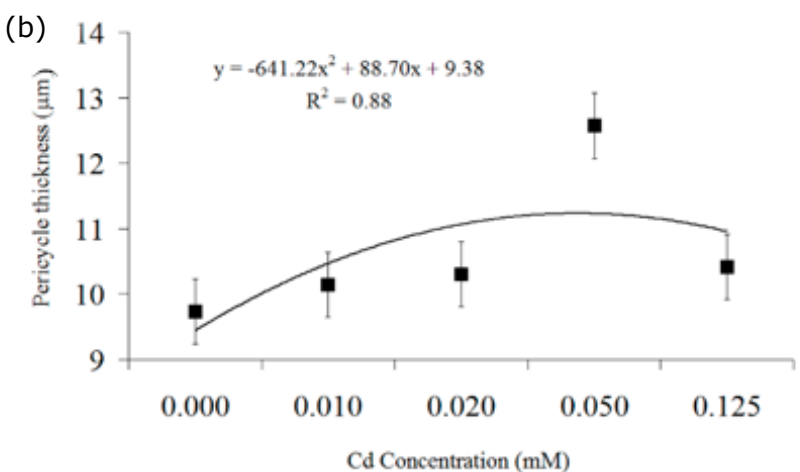
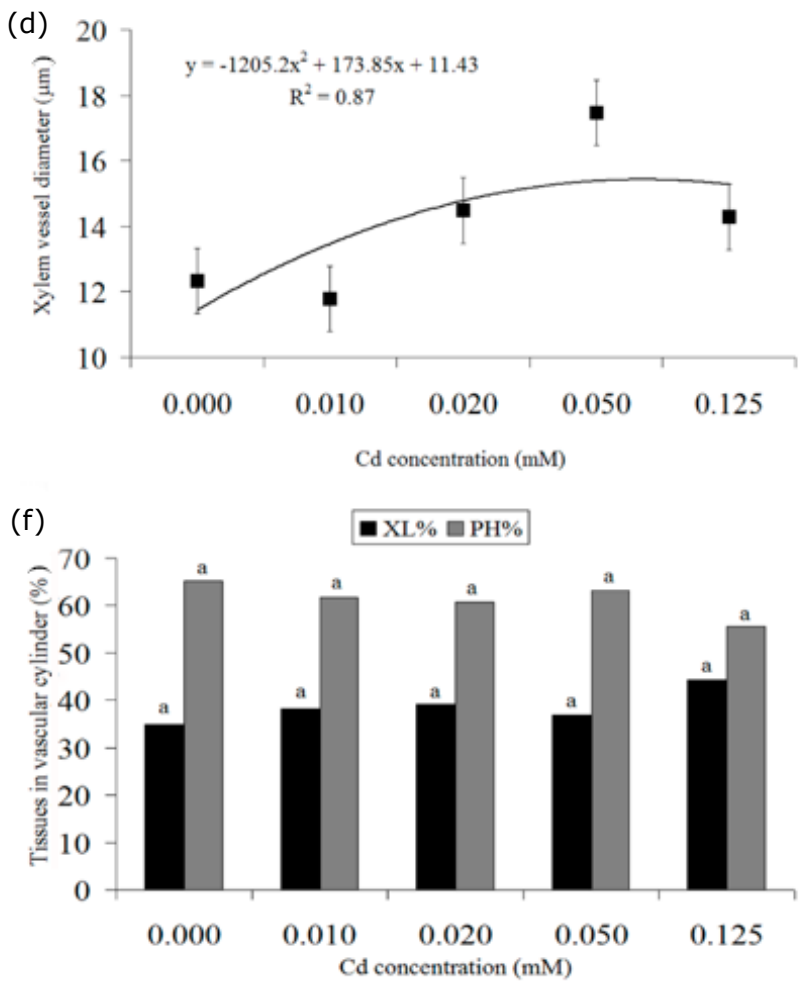

Figure 3. Root anatomy of S. molle seedlings grown under different $\mathrm{Cd}$ concentrations, evaluated in terms of endodermis thickness (a), pericycle thickness (b), cortex thickness (c), xylem vessel diameter (d), percent of root filled by vascular cylinder (e), and percent xylem and phloem in the vascular cylinder (f). Means followed by the same letter did not differ significantly according to the Scott-Knott test $(p>0.05)$. Error bars indicate standard error values. Coefficients of variation were $11.60 \%$ (a), $10.50 \%$ (b), $9.92 \%$ (c), $13.97 \%$ (d), $7.55 \%$ (e), and $15.76 \%$ (f).

\section{DISCUSSION}

Schinus molle showed tolerance to Cd during seed germination, which, as reported in the literature, is a rare trait since this pollutant high toxicity to seed germination is well-known (Ali et al., 2015; Bautista et al., 2013; Chugh \& Sawhney, 1997). However, Cd tolerance in seeds depends on both their genotypes (Ahmad et al., 2012) and the concentration of the pollutant (Rossi et al., 2012). The number of species known to be Cd accumulators is remarkably lower when 
compared to those that accumulate other metals (Krämer, 2010). Therefore, discovering new Cd-tolerant species is important for the remediation of polluted areas. The tolerance of $S$. molle seeds to $\mathrm{Cd}$ is thus relevant to future studies concerning the remediation or reforestation of $\mathrm{Cd}$ contaminated environments.

Seedling growth is also an important component of $\mathrm{Cd}$ tolerance. In fact, $\mathrm{Cd}$ can reduce seedling biomass production (Ali et al., 2015; Anuradha \& Rao, 2007; Chugh \& Sawhney, 1997), and root and shoot lengths (Chugh \& Sawhney, 1997; He et al., 2008; Tao et al., 2015). Even tolerant species can show reduced seedling growth depending on the Cd concentration experienced (Rossi et al., 2012). In this study, $S$. molle seedlings maintained their overall growth under conditions of Cd contamination, and some growth parameters even increased. However, increased fresh mass and length with $\mathrm{Cd}$ treatment probably resulted from cell expansion only. Meristem activity during seedling growth must be further evaluated once cell production has stabilized to confirm these increased growth responses, since based on current knowledge $\mathrm{Cd}$ cannot stimulate growth. Furthermore, low Cd levels were previously observed to induce increased photosynthesis and anatomical modifications in the leaves of S. molle (Pereira et al., 2016). Although the detailed effects of Cd on seedlings' growth need to be further investigated, we can conclude that $S$. molle seedlings can be tolerant to this pollutant.

Part of a plant's strategy to overcome Cd toxicity is keep this element in the roots, thereby avoiding damage to the photosynthetic tissues in the leaves. Mature S. molle plants proved to be tolerant to $\mathrm{Cd}$ and $\mathrm{Pb}$ in previous studies and could accumulate most of the $\mathrm{Pb}$ to which they were exposed in their roots (Pereira et al., 2013, 2016). Moreover, $\mathrm{Cd}$ accumulation in the roots has been reported in several different plant species (Rivera-Becerril et al., 2002; Rossi et al., 2012). A plant's capacity to limit heavy metal transport from the roots to the shoot is related to the thickening of root cortex and endodermis (Pereira et al., 2013; Ribeiro et al., 2015). Likewise, endodermis cells contain suberin, which reduces water and nutrient flux within the roots (Naseer et al., 2012). Thus, the thickening of root tissues produces a stronger barrier to water flux, which in turn reduces $\mathrm{Cd}$ transport to the shoot.

Reduced vascular cylinder diameter can limit the roots' hydraulic transport capacity, what may further constrain $\mathrm{Cd}$ to the roots. However, larger xylem vessel diameter can conversely increase xylem water flux as a compensatory mechanism, as increased xylem vessel diameter is related to having a larger hydraulic conductivity (Zach et al., 2010). Therefore, as the proportion of xylem and phloem did not change in this study and the overall root anatomy was preserved, no real signs of Cd toxicity were evident in the roots of the $S$. molle seedlings examined.

\section{CONCLUSION}

Based on this study's results, Schinus molle germination and seedling growth are not affected by Cd. Cadmium promoted anatomical modifications in the root tissues of seedlings, but no toxic effects were found. Therefore, Schinus molle is a Cd-tolerant potential candidate for use in the remediation or reforestation of areas with Cd-polluted soils.

\section{ACKNOWLEDGEMENTS}

The authors thank Conselho Nacional de Desenvolvimento Científico e Tecnológico (CNPq), Coordenação de Aperfeiçoamento de Pessoal de Nível Superior (Capes), and Fundação de Amparo à Pesquisa do Estado de Minas Gerais (Fapemig) for funding and research grants awarded to complete the present study.

\section{SUBMISSION STATUS}

Received: 18 Apr. 2017

Accepted: 24 Nov. 2018

Associate editor: Evânia Galvão Mendonça

\section{CORRESPONDENCE TO}

\section{Fabrício Pereira}

Universidade Federal de Alfenas (Unifal), Rua Gabriel Monteiro da Silva, 700, CEP 37130-000, Alfenas, MG, Brasil

e-mail: gabrielbaroni92@gmail.com

\section{REFERENCES}

Ahmad I, Akhtar MJ, Zahir ZA, Jami A. Effect of cadmium on seed germination and seedling growth of four wheat (Triticum aestivum $\mathrm{L}$.) cultivars. Pakistan Journal of Botany 2012; 44(5): 1569-1574.

Ali B, Deng X, Hu X, Gill RA, Ali S, Wang S, Zhou W. Deteriorative effects of cadmium stress on antioxidant system and cellular structure in germinating seeds of Brassica napus L. Journal of Agriculture Science and Technology 2015; 17(17): 63-74.

Anuradha S, Rao SSR. The effect of brassinosteroids on radish (Raphanus sativus L.) seedlings growing under cadmium stress. Plant Soil and Environment 2007; 53(11): 465-472. 10.17221/2307-PSE

Bautista OV, Fischer G, Cárdenas JF. Cadmium and chromium effects on seed germination and root elongation in lettuce, spinach and Swiss chard. Agronomía Colombiana 2013; 31(1): 48-57.

Benavides MP, Gallego SM, Tomaro ML. Cadmium toxicity in plants. Brazilian Journal of Plant Physiology 2005; 17:21-34.

Chugh LK, Sawhney SK. Effect of cadmium on germination, amylases and rate of respiration of germinating pea seeds. Environmental Pollution 1997; 92(1): 1-5. 10.1016/0269-7491(95)00093-3 
Demelash L, Tigabu M, Odén PC. Enhancing germinability of Schinus molle L. seed lot from Ethiopia with specific gravity and IDS techniques. New Forests 2003; 26: 33-41. 10.1023/A:1024486204058

Ferreira DF. Sisvar: a computer statistical analysis system. Ciência e Agrotecnologia 2011; 35(6): 1039-1042. 10.1590/S141370542011000600001

Gonzälez-Oreja JA, Rozas MA, Alkorta I, Garbisu C. Dendroremediation of heavy metal polluted soils. Reviews on Environmental Health 2008; 23(3): 223-234. 10.1515/ REVEH.2008.23.3.223

He J, Ren Y, Zhu C, Jiang D. Effects of cadmium stress on seed germination, seedling growth and seed amylase activities in rice (Oryza sativa). Rice Science 2008; 15(4): 319-325. 10.1016/S16726308(09)60010-X

Iponga DM, Milton SJ, Richardson DM. Superiority in competition for light: a crucial attribute defining the impact of the invasive alien tree Schinus molle (Anacardiaceae) in South African savanna. Journal of Arid Environments 2008; 72(5): 612-623. 10.1016/j. jaridenv.2007.10.001

Johansen DA. Plant microtechnique. New York: McGraw-Hill; 1940.

Krämer U. Metal hyperaccumulation in plants. Annual Review of Plant Biology 2010; 61: 517-534. 10.1146/annurev-arplant-042809-112156

Malan HL, Farrant JM. Effects of the metal pollutants cadmium and nickel on soybean seed development. Seed Science Research 1998; 8(4): 445-453. 10.1017/S0960258500004414

Mangkoedhadjo S. Jatropha curcas L. for phytoremediation of lead and cadmium polluted soil. World Applied Sciences Journal 2008; 4(4): 519-522

Moïse JA, Han S, Gudynaite-Savitch L, Johnson DA, Miki BLA. Seed coats: structure, development, composition, and biotechnology. In Vitro Cellular \& Developmental Biology-Plant 2005; 41: 620-644. 10.1079/IVP2005686

Naseer S, Lee Y, Lapierre C, Franke R, Nawrath C, Geldner N. Casparian strip diffusion barrier in Arabidopsis is made of a lignin polymer without suberin. Proceedings of the National Academy of Sciences 2012; 109(25): 10101-10106. 10.1073/pnas.1205726109

Pereira FJ, Castro EM, Oliveira C, Pires MF, Pereira MP, Ramos SJ, Faquin V. Lead tolerance of water hyacinth (Eichhornia crassipes
Mart. - Pontederiaceae) as defined by anatomical and physiological traits. Anais da Academia Brasileira de Ciências 2014; 86(3): 1423 1433. 10.1590/0001-3765201420140079

Pereira MP, Pereira FJ, Corrêa FF, Oliveira C, Castro EM, Barbosa S. Lead tolerance during germination and early growth of the Brazilian peppertree and the morpho-physiological modifications. Revista de Ciências Agrárias 2013; 56: 1-8. 10.4322/rca.2013.084

Pereira MP, Rodrigues LCA, Corrêa FF, Castro EM, Ribeiro VE, Pereira FJ. Cadmium tolerance in Schinus molle trees is modulated by enhanced leaf anatomy and photosynthesis. Trees 2016; 30(3): 807-814. 10.1007/s00468-015-1322-0

Ribeiro ES, Pereira MP, Castro EM, Baroni GR, Corrêa FF, Pereira FJ. Relações da anatomia radicular na absorção, no acúmulo e na tolerância ao chumbo em Echinodorus grandiflorus. Revista Brasileira de Engenharia Agrícola e Ambiental 2015; 19(6): 605-612. 10.1590/1807-1929/agriambi.v19n6p605-612

Rivera-Becerril F, Calantzis C, Turnau K, Caussanel J, Belimov AA, Gianinazzi S, Strasser RJ et al. Cadmium accumulation and buffering of cadmium-induced stress by arbuscular mycorrhiza in three Pisum sativum L. genotypes. Journal of Experimental Botany 2002; 53(371): 1177-1185.

Rossi SC, Lagoa AMMA, Schiavinato MA. Tolerance to cadmium in the germination and development of jack beans. Revista de Ciências Agrárias 2012; 55(2): 142-147. 10.4322/rca.2012.042

Silva AS, Techio VH, Castro EM, Faria MR, Palmieri MJ. Reproductive, cellular, and anatomical alterations in Pistia stratiotes L. plants exposed to cadmium. Water, Air \& Soil Pollution 2013; 224(3): 1454. 10.1007/s11270-013-1454-Z

Tao L, Guo M, Ren J. Effects of cadmium on seed germination, coleoptile growth, and root elongation of six pulses. Polish Journal of Environmental Studies 2015; 24(1): 255-299. 10.15244/pjoes/29942

Zach A, Schuldt B, Brix S, Horna V, Culmsee H, Leuschner C. Vessel diameter and xylem hydraulic conductivity increase with tree height in tropical rainforest trees in Sulawesi, Indonesia. Flora 2010; 205(8): 506-512. 10.1016/j.flora.2009.12.008

Zhang XX, Li CJ, Nan ZB. Effects of cadmium stress on seed germination and seedling growth of Elymus dahuricus infected with the Neotyphodium endophyte. Science China Life Sciences 2012; 55(9): 793-799. 10.1007/s11427-012-4359-y 